\title{
Impact of moisture divergence on systematic errors in precipitation around the Tibetan Plateau in a general circulation model
}

\author{
Yi Zhang ${ }^{1,2} \cdot \operatorname{Jian~} \mathrm{Li}^{1}$
}

Received: 19 May 2015 / Accepted: 20 January 2016 / Published online: 10 February 2016

(c) The Author(s) 2016. This article is published with open access at Springerlink.com

\begin{abstract}
Current state-of-the-art atmospheric general circulation models tend to strongly overestimate the amount of precipitation around steep mountains, which constitutes a stubborn systematic error that causes the climate drift and hinders the model performance. In this study, two contrasting model tests are performed to investigate the sensitivity of precipitation around steep slopes. The first model solves a true moisture advection equation, whereas the second solves an artificial advection equation with an additional moisture divergence term. It is shown that the orographic precipitation can be largely impacted by this term. Excessive (insufficient) precipitation amounts at the high (low) parts of the steep slopes decrease (increase) when the moisture divergence term is added. The precipitation changes between the two models are primarily attributed to large-scale precipitation, which is directly associated with water vapor saturation and condensation. Numerical weather prediction experiments using these two models suggest that precipitation differences between the models emerge shortly after the model startup. The implications of the results are also discussed.
\end{abstract}

Keywords Precipitation - Model errors - Moisture divergence $\cdot$ Steep terrain $\cdot$ General circulation model

Yi Zhang

zhange@camscma.cn; zhangyi@lasg.iap.ac.cn

1 LaSW, Chinese Academy of Meteorological Sciences, China Meteorological Administration, 46 Zhongguancun South St., Beijing 100081, China

2 LASG, Institute of Atmospheric Physics, Chinese Academy of Sciences, Beijing, China

\section{Introduction}

Despite the rapid development of atmospheric general circulation models (AGCMs), systematic model errors in the climatological mean state remain a major challenge to the scientific community (e.g., Huang et al. 2007; Xie et al. 2012; Magnusson et al. 2013a; Zhang and Li 2013). The overestimation of precipitation around regions with steep orography is an evident instance of such systematic model errors in current state-of-the-art GCMs (e.g., Su et al. 2013; Mehran et al. 2014). The ensemble of Coupled Model Intercomparison Project Phase 3 (CMIP3) models overestimates the amount of precipitation over the Tibetan Plateau by up to $100 \%$ (Xu et al. 2010). This is also true for other regions with high mountains, e.g., the Andes mountains, where both regional and global models tend to produce excessive precipitation (Alves and Marengo 2010; Gulizia and Camilloni 2015).

Systematic model errors cause the model climate to drift away from the real-world climate, hindering the modeling and forecasting performance. Precipitation is arguably one of the most basic physical properties that global weather and climate models are expected to simulate and predict well. Precipitation typically reflects processes associated with water vapor condensation, latent heat release and cloud occurrence, which fundamentally influence the water balance and radiative forcing that are the essential driving forces of atmospheric circulation. They in turn may affect physical processes that are responsible for precipitation. To mitigate systematic model errors in orographic precipitation, the model must be fine-tuned (e.g., Mauritsen et al. 2012) such that it can adequately simulate precipitation amounts around mountainous regions.

There are multiple factors that may affect the simulation of orographic precipitation, including the computational error associated with the terrain-following vertical 
coordinate (the near-cancellation of two large terms in the calculation of the horizontal pressure gradient) at the lowest model levels (Danard et al. 1993), and the decoupling between advection and condensation processes (Codron and Sadourny 2002). Moreover, Yu et al. (2015) demonstrated the sensitivity of orographic precipitation to the choice of different advection schemes. In this study, we first revisit the problem of overestimated orographic precipitation in GCMs and find an effective solution to mitigate the precipitation bias and then demonstrate the implications.

\section{Identification of the problem}

The overestimation of orographic precipitation persists in latest CMIP5 models. As shown in Fig. 1, in 23 models participating in CMIP5 (here, we choose results from the Atmospheric Model Intercomparison Project (AMIP) experiments), high standard deviation (STDDEV; Fig. 1a) values of the annual mean total precipitation amount are found in regions with elevated topography (e.g., the southern edge of the Tibetan Plateau and the Andes Mountains), suggesting large discrepancies in simulations of orographic precipitation. Figure $1 \mathrm{~b}$ shows the root-mean-square error
(RMSE) between 23 models and the satellite observational dataset (Tropical Rainfall Measuring Mission; TRMM; Huffman et al. 2007). The RMSE at each grid point is calculated by: $R M S E=\sqrt{\frac{1}{n} \sum_{i=1}^{n}\left[p(i)-p_{0}\right]^{2}}$, where $n$ denotes the number of models, $p(i)$ denotes the annual mean precipitation amount from each model, and $p_{0}$ denotes the annual mean precipitation amount from TRMM. Compared with observations, the model group shows large magnitude of errors at the same steep mountainous regions with high STDDEV values. Figure 1c shows the differences in the precipitation amounts between the ensemble of models and the observation. Significant positive errors are observed at the steep mountainous regions with large STDDEV and RMSE values; that is, most models tend to produce excessive amounts of precipitation around steep terrains.

The discrepancy of orographic precipitation exists not only in long-term climate simulations but also in the reanalysis data, in which surface precipitation is generated by model physics that is typically forced by relatively more realistic large-scale circulations and is only integrated for a few days. Figure 2 shows the annual mean precipitation biases, derived from the reanalysis datasets, ERA40 and NCEP2, against the TRMM observation. Both datasets overestimate
Fig. 1 a Standard deviation and b root-mean-square error values of annual mean precipitation amount (unit: $\mathrm{mm} \mathrm{day}^{-1}$ ) in 23 CMIP5 models, $\mathbf{c}$ the difference of annual mean precipitation amount between the model ensemble and observational result
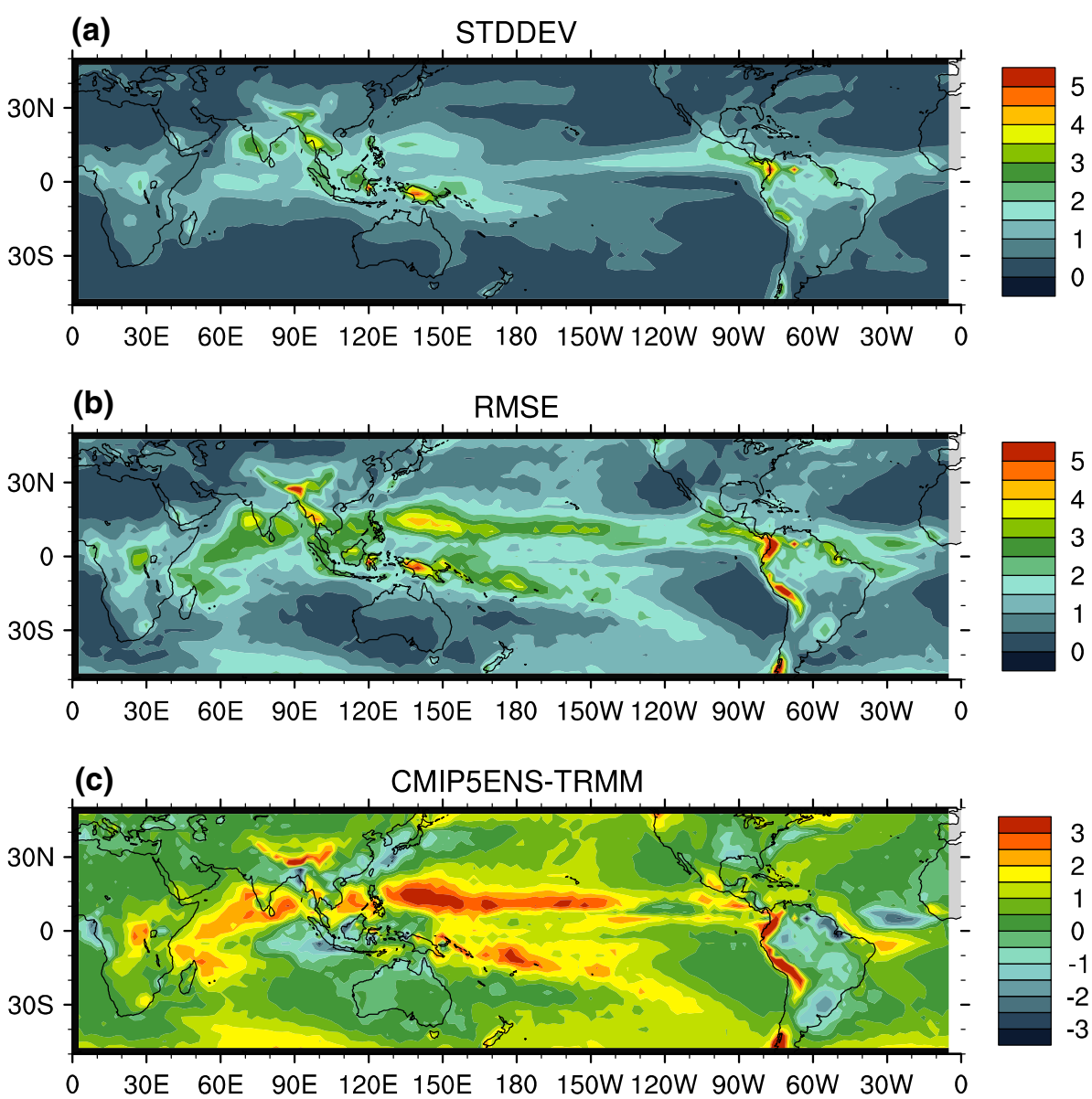

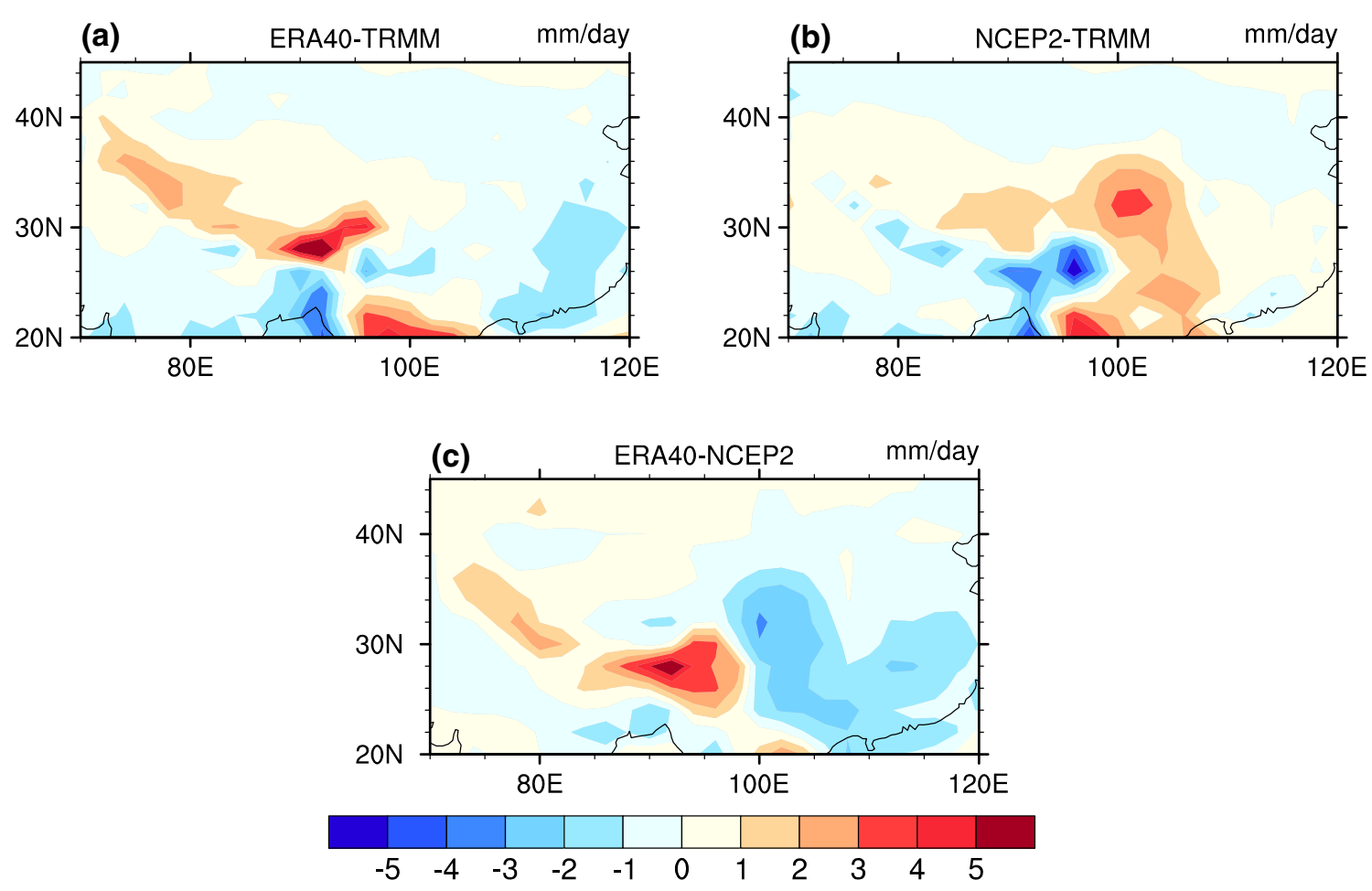

Fig. 2 Differences in annual mean precipitation amounts between a ERA40 and TRMM, b NCEP2 and TRMM, c ERA40 and TRMM, unit: $\mathrm{mm}$ day $^{-1}$

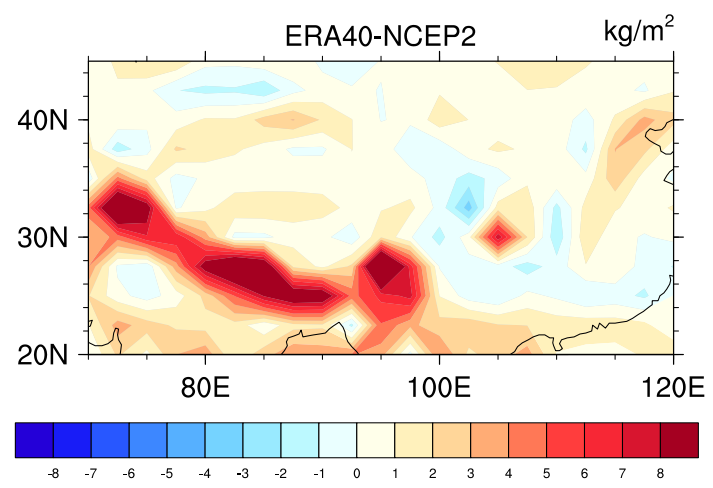

Fig. 3 Difference in the annual mean column precipitable water content $\left(\mathrm{kg} \mathrm{m}^{-2}\right)$ between ERA40 and NCEP2

the precipitation amounts over the main body of the Tibetan Plateau when compared with TRMM. In contrast, the results in the steep southern edge of the plateau are quite different. ERA40 (Fig. 2a) indicates higher amounts of precipitation, whereas NCEP2 (Fig. 2b) indicates fewer amounts. More interestingly, the differences in precipitation (Fig. 2c) over this region well corresponds with the positive differences in the column precipitable water contents (Fig. 3). This result suggests that orographic precipitation appears well sensitive to the moisture content around a steep terrain. Hence, altering the moisture content around steep slopes could possibly change the orographic precipitation simulation. Next, the question is how to appropriately tune moisture content and related precipitation around elevated topography.

As we understand, large mountains can cause considerable friction and drag to the surrounding atmosphere, leading to divergent airflows. Such airflows are primary dynamical sources that can regulate the moisture field around mountainous regions. Hence, if the moisture divergence associated with airflows around mountains can be readjusted, precipitation may change because of the redistribution of water vapor. Now, the question becomes: if we artificially manipulate the moisture divergence, will orographic precipitation become more realistic? This paper will address this question using an AGCM.

The remainder of this paper is organized as follows. Section 3 describes the model, experimental design and data. Section 4 presents the results. Finally, the discussion and conclusions are given in Sect. 5.

\section{Models, experimental design and data}

\subsection{Models}

The model used in this study is the Community Atmosphere Model (CAM), version 5.1. CAM5 is a component of the Community Earth System Model (CESM) 
developed at the National Center for Atmospheric Research (NCAR) with many external collaborators. The model uses a default finite-volume (FV) dynamical core (Lin 2004) with a hybrid sigma-pressure vertical coordinate (Simmons and Burridge 1981) that has 30 levels with a top at $2.255 \mathrm{hPa}$. Almost all parameterizations in CAM5 have been updated from the CAM4 version, except the deep convection scheme (Zhang and McFarlane 1995; Richter and Rasch 2008; Neale et al. 2008). CAM5 features (1) a new shallow convection scheme and a new moist turbulence scheme (Bretherton and Park 2009) developed by the University of Washington (Park and Bretherton 2009); (2) a two-moment cloud microphysics scheme (Morrison and Gettelman 2008; Gettelman et al. 2008) and a cloud macrophysics scheme (Park et al. 2014) for the parameterizations of clouds; and (3) an open source Rapid Radiative Transfer Model for GCM (RRTMG) package developed by the Atmospheric and Environmental Research (AER) incorporation is used as the radiation module (Mlawer et al. 1997; Iacono et al. 2008). A new modal aerosol module is also implemented in CAM5 (Liu et al. 2012).

Instead of its default FV dynamical core, an alternative Eulerian spectral transform core is used in this study. It is truncated at a T266 (approximately $0.45^{\circ} \times 0.45^{\circ}$ ) horizontal resolution with a hybrid sigma-pressure vertical coordinate that has the same vertical levels as those in the FV core. The spectral CAM5 model is a three-time-level Eulerian model that uses a spectral transform method (Machenhauer 1979) to solve spatial partial differences in governing equations. In addition, this model uses a shape-preserving, but not mass-conserving, semi-lagrangian transport (SLT) method (Williamson and Rasch 1989, 1994) to solve the advection (transport) equation. Zhang et al. (2015) compared the simulated local climate over eastern China between the spectral and FV CAM5 in several aspects (e.g., clouds and circulations). The two models generally produce similar climate except for some minor regional differences. In this study, the sensitivity test will be based on the advection equation of the spectral CAM5.

Generally, the moisture prognostic equation in a threedimensional (3D) space is formulated as follows:

$\frac{\partial q}{\partial t}=-\vec{V}_{3} \nabla_{3} q-Q_{2} / L$

where $q$ denotes the water vapor mixing ratio, $t$ denotes the time, $\vec{V}_{3}$ is the $3 \mathrm{D}$ velocity vector, and $\nabla_{3}$ is a $3 \mathrm{D}$ hamiltonian operator. The first right-side term $\left(-\vec{V}_{3} \nabla_{3} q\right)$ is the water vapor advection and is calculated by an advection scheme in the dynamical core. The rightmost term $-Q_{2} / L$ denotes the apparent moisture sink $\left(Q_{2}\right.$; Yanai et al. 1973) scaled by the constant latent heat of evaporation/condensation $(L)$, which can be determined from the model physics.
The SLT method used in spectral CAM5 directly solves the advection Eq. (1).

To manipulate the moisture content around a steep terrain, an additional moisture divergence term is added at the right side of Eq. (1); if we ignore the source/sink term hereafter, Eq. (1) transforms to:

$\frac{\partial q}{\partial t}=-\vec{V}_{3} \nabla_{3} q-q \nabla_{3} \cdot \vec{V}_{3}=-\nabla_{3} \cdot\left(\vec{V}_{3} q\right)$

where $-q \nabla_{3} \cdot \vec{V}_{3}$ is a 3D water vapor divergence term. By adding this term, regions with divergent flows will lose moisture, whereas regions with convergent flows will gain moisture. The combination of moisture advection and divergence terms yields a flux-form term $-\nabla_{3} \cdot\left(\vec{V}_{3} q\right)$. Therefore, in our contrast tests, the control experiment has to solve Eq. (1), whereas the sensitivity experiment has to solve Eq. (2).

To more conveniently solve these two equations in a consistent manner, we use an alternative transport method based on the flux-form finite-difference, called "Two-step Shape Preserving Advection Scheme" (TSPAS; Yu 1994), to solve Eq. (1), instead of the default SLT algorithm. The modification and implementation of TSPAS in spectral CAM5 is described in detail by Zhang et al. (2013). Hereafter, this modified model is referred to as M-CAM5. Yu et al. (2015) compared the simulated summer precipitation between M-CAM5 and CAM5, and suggested several improvements of M-CAM5 in simulating orographic precipitation around the Tibetan Plateau. Further, this paper will investigate the larger sensitivity produced by this moisture divergence term, especially for the annual mean state.

The reason for using this scheme is because that a fluxform scheme can be very easy and efficient to solve both Eqs. (1) and (2). Given the continuity equation of a generic vertical coordinate used by CAM5 (Kasahara 1974; Simmons and Burridge 1981), which is:

$\frac{\partial\left(\frac{\partial p}{\partial \eta}\right)}{\partial t}+\nabla_{2} \cdot\left(\vec{V}_{2} \frac{\partial p}{\partial \eta}\right)+\frac{\partial \dot{\eta} \frac{\partial p}{\partial \eta}}{\partial \eta}=0$

where $p$ denotes the pressure, $\eta$ denotes the vertical coordinate of the model, $\frac{\partial}{\partial \eta}$ is the vertical partial difference, $\dot{\eta}$ is the vertical velocity in the vertical coordinate, and $\vec{V}_{2}$ and $\nabla_{2}$ are the two-dimensional velocity and hamiltonian operator, respectively. Equation (3) is equivalent to Eq. (4) if we multiply $q$ at both sides, that is:

$q \frac{\partial\left(\frac{\partial p}{\partial \eta}\right)}{\partial t}+q \nabla_{2} \cdot\left(\vec{V}_{2} \frac{\partial p}{\partial \eta}\right)+q \frac{\partial \dot{\eta} \frac{\partial p}{\partial \eta}}{\partial \eta}=0$

Moreover, the advection equation in Eq. (1) can be expanded as: 
$\frac{\partial q}{\partial t}+\vec{V}_{2} \nabla_{2} q+\dot{\eta} \frac{\partial q}{\partial \eta}=0$

and Eq. (5) is equivalent to Eq. (6) if we multiply $\frac{\partial p}{\partial \eta}$ at both sides:

$\frac{\partial p}{\partial \eta} \frac{\partial q}{\partial t}+\frac{\partial p}{\partial \eta} \vec{V}_{2} \nabla_{2} q+\frac{\partial p}{\partial \eta} \dot{\eta} \frac{\partial q}{\partial \eta}=0$

Thus, by combining Eqs. (4) and (6), we obtain:

$$
\begin{aligned}
& q \frac{\partial\left(\frac{\partial p}{\partial \eta}\right)}{\partial t}+q \nabla_{2} \cdot\left(\vec{V}_{2} \frac{\partial p}{\partial \eta}\right)+q \frac{\partial \dot{\eta} \frac{\partial p}{\partial \eta}}{\partial \eta}+\frac{\partial p}{\partial \eta} \frac{\partial q}{\partial t} \\
& \quad+\frac{\partial p}{\partial \eta} \vec{V}_{2} \nabla_{2} q+\frac{\partial p}{\partial \eta} \dot{\eta} \frac{\partial q}{\partial \eta}=0
\end{aligned}
$$

Obviously, Eq. (7) is an expansion of the flux-form Eq. (8):

$\frac{\partial\left(q \frac{\partial p}{\partial \eta}\right)}{\partial t}+\nabla_{3} \cdot\left(\vec{V}_{3} q \frac{\partial p}{\partial \eta}\right)=0$

Let $Q=q \frac{\partial p}{\partial \eta}$ and move $\nabla_{3} \cdot\left(\vec{V}_{3} q \frac{\partial p}{\partial \eta}\right)$ to the right side. Thus, we obtain:

$\frac{\partial Q}{\partial t}=-\nabla_{3} \cdot\left(\vec{V}_{3} Q\right)$

Equations (2) and (9) have the same form but with different transported terms ( $q$ versus $Q$ ). Equation (9), which is equivalent to Eq. (1) that is solved by SLT in CAM5, can be directly solved by an eulerian flux-form advection scheme such as TSPAS. Thus, if we replace the transported term $Q$ with $q$, TSPAS can directly solve Eq. (2). We call the model whose transport scheme solves Eq. (2) as MqCAM5. It is exactly the same as M-CAM5 except that the transported term is $q$ instead of $Q$. The differences in orographic precipitation between these two models are the primary focus of this study.

\subsection{Experiments and data}

In this work, three experiments were conducted for three model configurations, respectively. CAM5, M-CAM5 and Mq-CAM5 are integrated from 1979 to 1988 with prescribed sea-surface temperature. The analysis period is 1980-1988 to avoid the impact of initial conditions. We focus on the annual mean state of the precipitation. The observational dataset is taken from TRMM 3B42 (Huffman et al. 2007). Although the observational results are shown, the main goal of the sensitivity experiments is not to check their resemblance to the observations, but to understand how orographic precipitation in a GCM can be impacted. CAM5 and M-CAM5 are compared only to show the common model biases. The differences between MqCAM5 and M-CAM5 are the primary focus of this study.
By comparing the results from these two models, the key factors that regulate orographic precipitation will be confirmed. This scientific finding will guide the future practice of tuning the model simulations and forecasts.

\section{Results}

Figure $4 \mathrm{a}$ shows the differences in the annual mean precipitation amount between CAM5 and TRMM around the Tibetan Plateau. Similar to most CMIP5 models, CAM5 overestimates the annual mean precipitation around high mountains. At the southern edge of the Tibetan Plateau, CAM5 produces excessive precipitation amounts above the 500-m contour level and less precipitation below it. At the eastern steep edge of the plateau, CAM5 produces excessive precipitation amounts above the 2000-m contour line and insufficient amounts below it. This reflects a key problem that the model tends to overestimate the orographic precipitation amounts at the high parts of steep slopes, whereas it underestimates the amount of precipitation at the low parts.

Figure $4 \mathrm{~b}$ shows the difference between M-CAM5 and TRMM. In the annual mean state, although the biases are generally similar to that in Fig. 4a, M-CAM5 decreases the positive precipitation error at the southern edge of
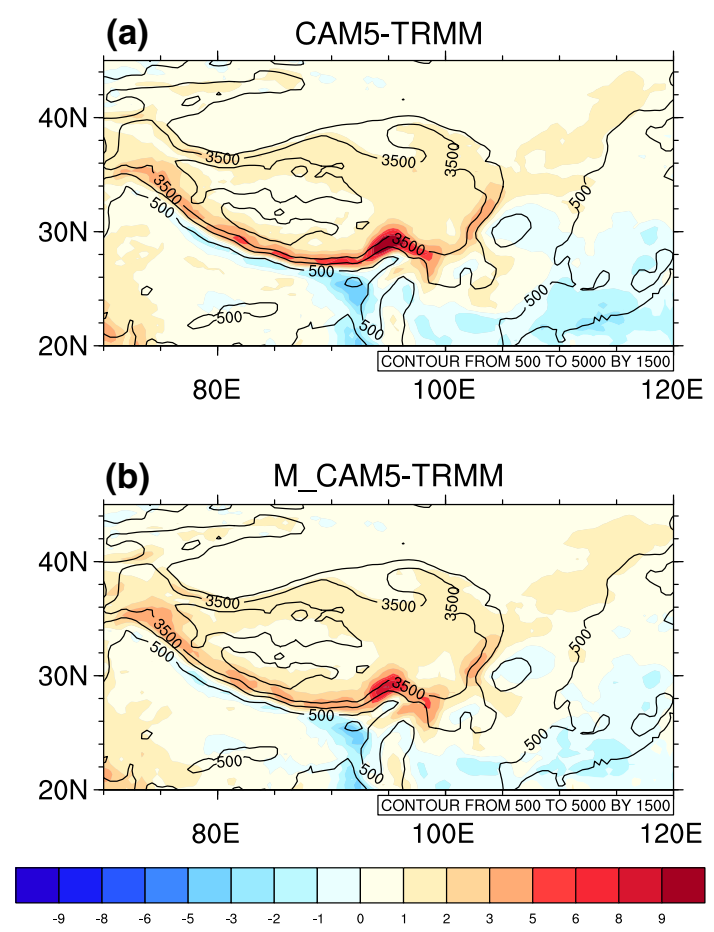

Fig. 4 Differences of the annual mean total precipitation amount $\left(\mathrm{mm} \mathrm{day}{ }^{-1}\right)$ between a CAM5 and TRMM, b M-CAM5 and TRMM over East Asia. The black contour line denotes the orographic height in meters 
Fig. 5 Differences of the annual mean total precipitation amount (color shaded, unit: $\mathrm{mm} \mathrm{day}^{-1}$ ) between Mq-CAM5 and M-CAM5 for the a Tibetan Plateau and the Andes Mountain regions. The black contour line denotes the orographic height in meters
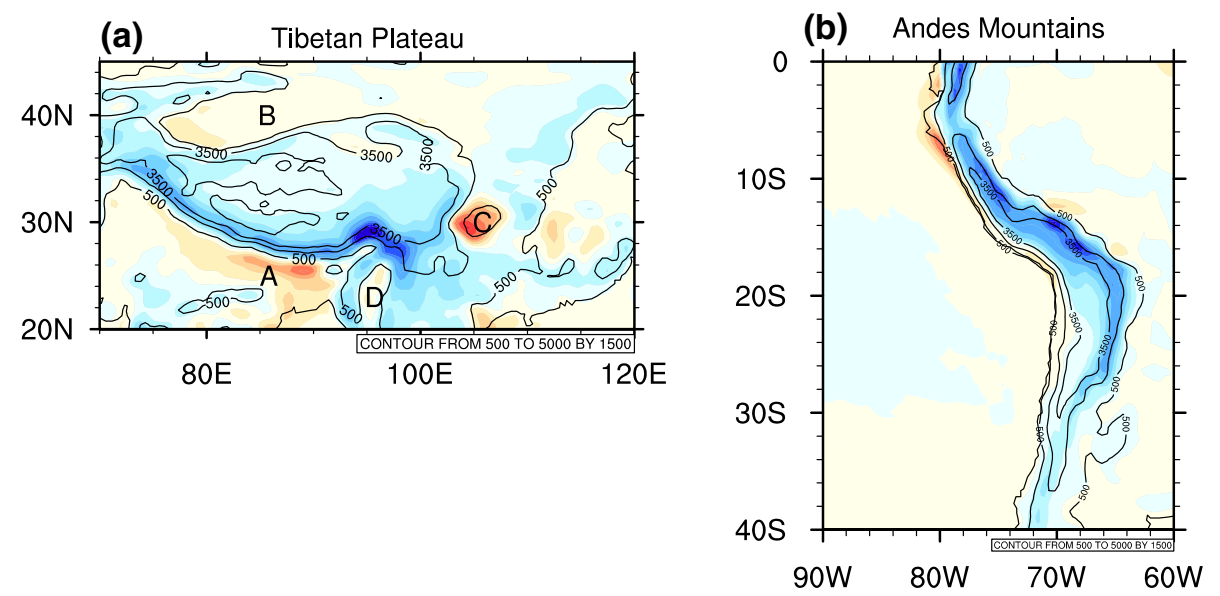

(a)

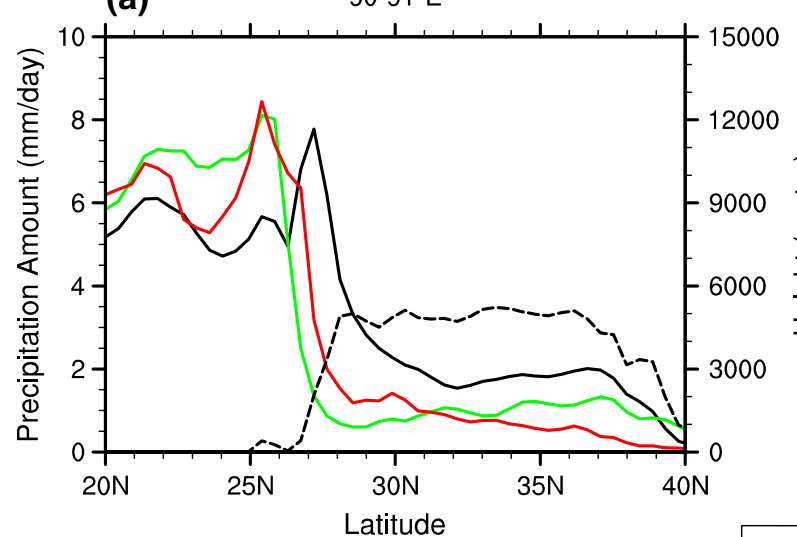

(b)

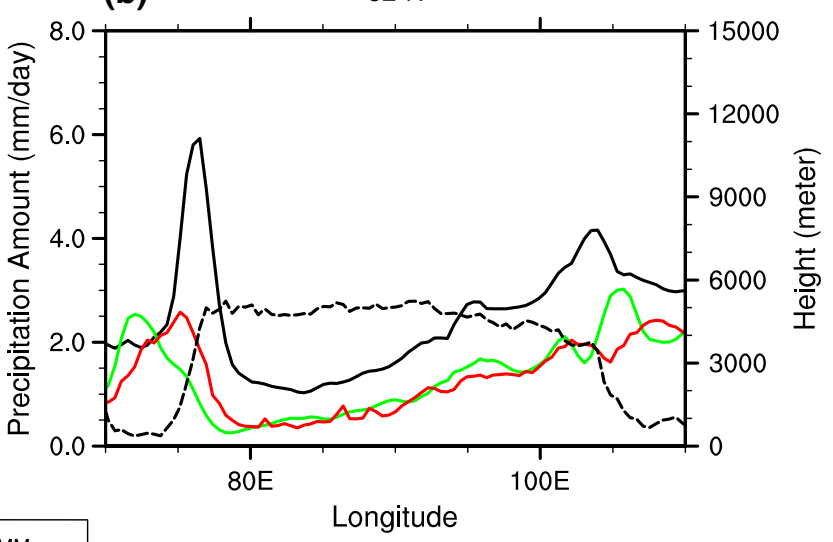

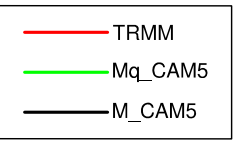

Fig. 6 Annual mean precipitation amount $\left(\mathrm{mm}\right.$ day $\left.^{-1}\right)$ a averaged between $90-91^{\circ} \mathrm{E}$ and $\mathbf{b}$ along $32^{\circ} \mathrm{N}$. The black dashed lines denote the orographic height in meters. The black, green, and red solid lines denote the precipitation amounts obtained from M-CAM5, MqCAM5 and TRMM, respectively

Positive differences are found below the 500-m contour line at the southern edge of the Tibetan Plateau. The main body of the Tibetan Plateau is primarily covered by negative differences, in contrast to the original positive bias in Fig. 4a. Over the Sichuan basin $\left(27^{\circ} \mathrm{N}-32^{\circ} \mathrm{N}, 103^{\circ} \mathrm{E}-108^{\circ} \mathrm{E}\right.$, region $\mathrm{C}$ ), which is on the lee side of the Tibetan Plateau, large positive differences also offset the minor negative bias between M-CAM5 and TRMM. Similar changes can also be found at the Andes Mountains (Fig. 5b), where large negative differences between Mq-CAM5 and M-CAM5 offset the original positive biases.

The results in Fig. 5 confirm that the additional moisture divergence term can effectively alter the climatological precipitation around steep mountains. With the addition 
of this term, the precipitation amounts at the high parts of the slope decrease, whereas those at the low parts of the slope increase. To show the details of the changes, a meridional transect through the Tibetan Plateau averaged over $90^{\circ} \mathrm{E}-91^{\circ} \mathrm{E}$ (Fig. 6a) and a zonal transect along $32^{\circ} \mathrm{N}$ (Fig. 6b) are respectively shown to better illustrate this point. As shown in Fig. 6a, at the steep southern edge of the Tibetan Plateau, more (less) precipitation is produced at the high (low) altitude regions in M-CAM5 (black line) as compared with TRMM (red line). Thus, the precipitation peak in M-CAM5 is situated at the north of that in the observation. In Mq-CAM5 (green line), the precipitation peak moves to the same location as in the observation. Moreover, M-CAM5 overestimates the precipitation amount over the main body of the plateau, whereas MqCAM5 yields significantly less precipitation amount in this region and closer to observation.

The zonal transect exhibits similar shifts. Compared with TRMM, M-CAM5 produces higher amounts of precipitation along the entire transect, especially at the highaltitude regions of the western and eastern steep edges. In
Mq-CAM5, the precipitation amounts at two peaks are significantly reduced, and the excessive precipitation over the main body of the Tibetan Plateau is also suppressed.

Precipitation in a GCM usually results from two different processes: (i) subgrid scale moist processes like moist convection and turbulence, which produce subgrid scale precipitation or the so-called convective precipitation that is typically associated with precipitating cumulus clouds, and (ii) the stratiform microphysics that generates the grid/ large-scale precipitation and is associated with water vapor condensation and saturation. By comparing the differences from various precipitation types, we see that the large-scale precipitation is responsible for the changes in the total precipitation from M-CAM5 to Mq-CAM5. As shown in Fig. 7a, b, the differences in the large-scale precipitation amount have a very similar spatial pattern to the differences of the total precipitation amount (Fig. 5). The four regions around the Tibetan Plateau (Fig. 7a) with positive values marked $\mathrm{A}, \mathrm{B}, \mathrm{C}, \mathrm{D}$ correspond to the same regions in Fig. 5a, and the main body of the plateau is covered by negative values. In the Andes Mountains (Fig. 7b), negative
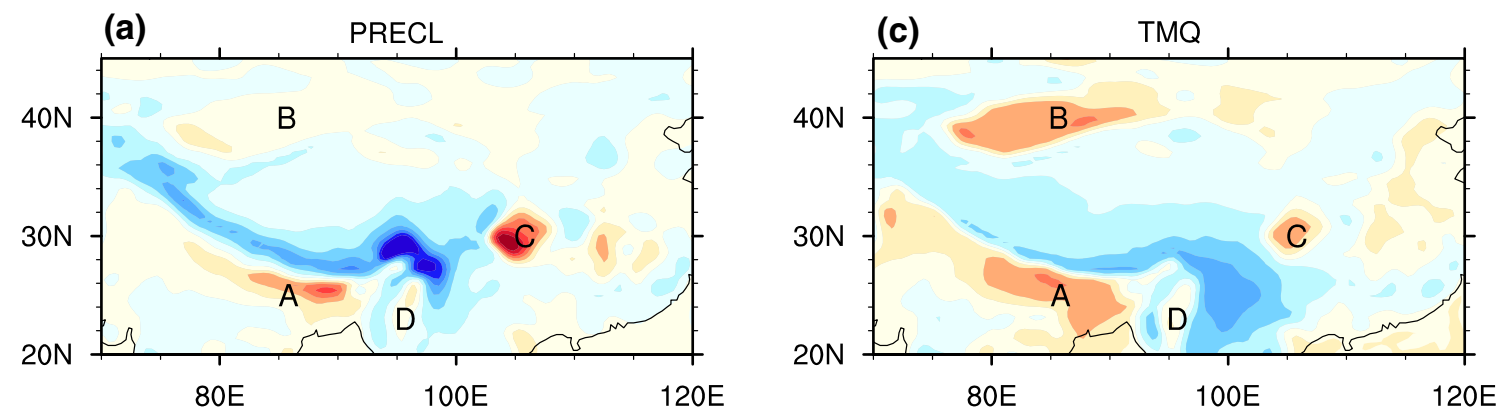

(b) PRECL
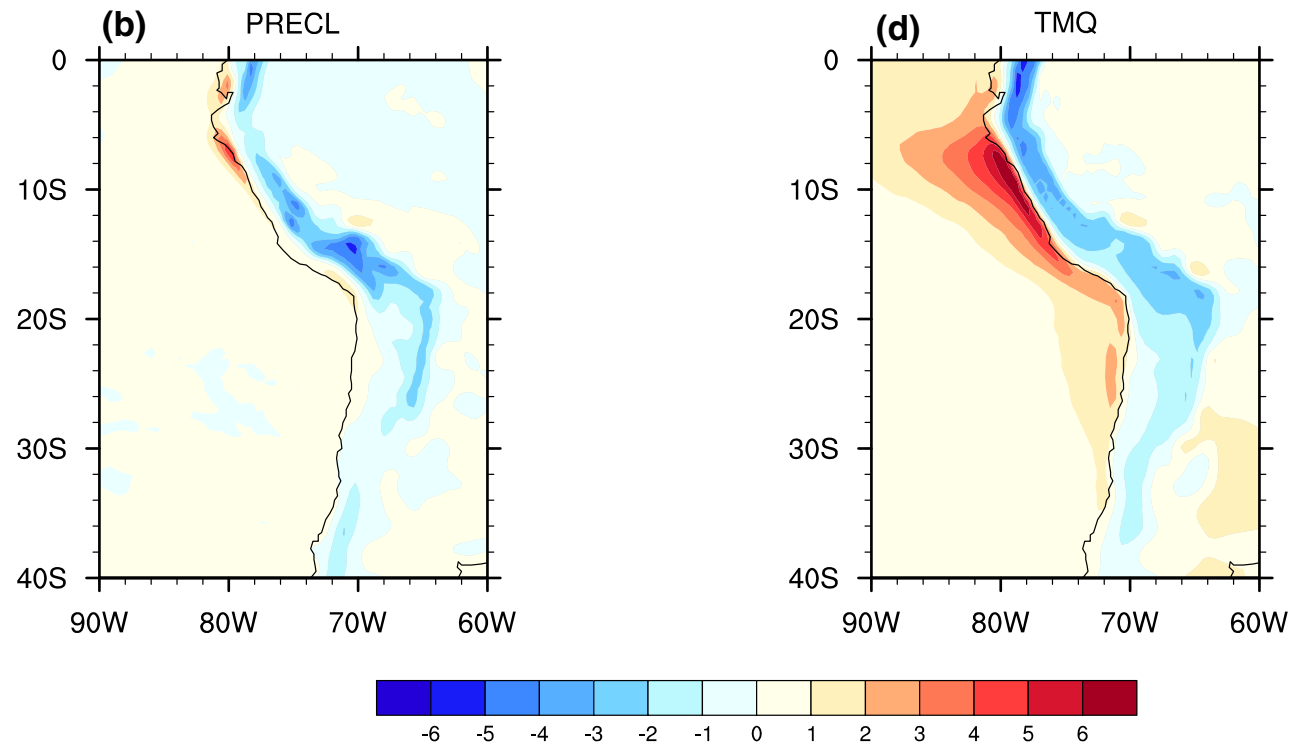

Fig. 7 a, b Same as Fig. 3 (except without the surface elevation) but for the large-scale precipitation amount (mm day ${ }^{-1}$ ), c, $\mathbf{d}$ same as a, b but for the vertically integrated moisture (TMQ) field, unit: $\mathrm{kg} \mathrm{m}^{-2}$ 
values dominate the high-altitude regions along the long and narrow range, in line with Fig. 5b. Hence, it is inferred that the precipitation differences are mainly attributed to the grid-scale saturation and condensation processes. The precipitation differences are likely regulated by the redistribution of water vapor content.

To confirm this, Fig. 7c, d show the same picture as Fig. 7a, b but for the vertically integrated moisture content. In the Tibetan Plateau (Fig. 7c), the main body of the plateau, especially the southern steep edge, exhibits negative differences, suggesting moisture dissipation over this region. The same four regions as in Fig. 5a are dominated by positive values, absorbing the dissipated moisture amounts from the mountain body. In the Andes Mountains (Fig. 7d), the main body of this narrow mountain range is dominated by negative values, also in accordance with the negative differences of the large-scale precipitation amount. Note that although the moisture content over the southeastern Pacific Ocean near the Peruvian coast also increased, the precipitation amount changed slightly. This is because the dominating stratocumulus cloud system in this region typically produces light precipitation in the form of drizzle. The results suggest that the additional moisture divergence term can effectively alter the moisture distribution around steep mountains, and regulate the resultant total precipitation amount via grid-scale saturation and condensation processes.

Because all results presented above are annual mean states, and considering that the climate system is a complex nonlinear system and climate errors may be the compensated result from errors in representing the various dynamical and physical processes in climate models, a better understanding of the model sensitivity should depend on the elimination of effects that arise from longer time-scale feedbacks (e.g., Phillips et al. 2004; Rodwell and Palmer 2007; Xie et al. 2012). In this approach, we can understand how soon the precipitation differences develop after the model initiation.

For this purpose, a group of numerical weather prediction (NWP) experiments was conducted. This approach assumes that large-scale atmospheric state fields in the early stage of the model integration are relatively realistic. Therefore, changes arising from longer time-scale feedbacks are eliminated, allowing us to investigate the model sensitivity at the early stage of the model integration. Because precipitation is frequent in the summer, the climatological mean of a single summer month (July) is enough to check the sensitivity. Hence, M-CAM5 and Mq-CAM5 are respectively initialized and started with the ERA-Interim data at the 0000 UTC of each day from June 28 to July 31 (1980-1988). The initialization method is to replace the atmospheric state variables (specific humidity, $\mathrm{U}$ and $\mathrm{V}$ winds, temperature, and surface pressure) in the initial data with those in the ERA-Interim data at the corresponding times. The model integrations produce forecasts over a three-day period. By taking the ensembles of day-2 (the 2nd day after initiating the model) and day-3 (the 3rd day after initiating the model) forecasts, the climatological means of July from 1980 to 1988 can be respectively calculated for the day- 2 and day- 3 ensembles. We only show results around the Tibetan Plateau as an example.

Figure $8 \mathrm{a}, \mathrm{b}$ show the precipitation differences between Mq-CAM5 and M-CAM5 obtained from the day-2 results.
Fig. 8 Differences in the precipitation amount $\left(\mathrm{mm} \mathrm{day}^{-1}\right)$ between Mq-CAM5 and M-CAM5 of the day-2 and day-3 ensembles, respectively for the total (PRECT) and largescale (PRECL) precipitation. Four regions marked $A, B, C$, $D$ around the Tibetan Plateau are shown and discussed in the context
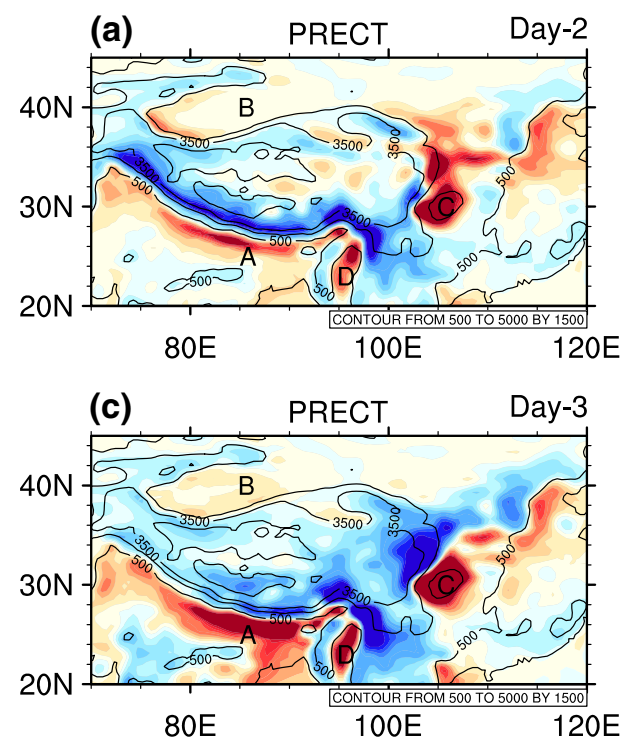
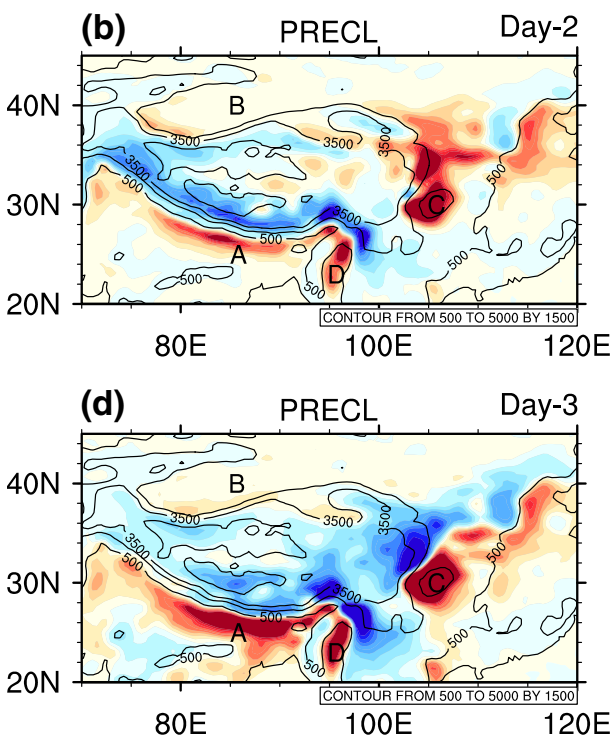

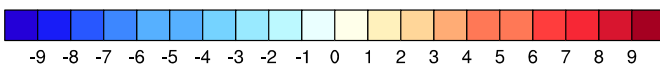


The total precipitation amount in Fig. 8a has a similar pattern to the long-term integration results in Fig. 5a. The precipitation amounts at the main body of the Tibetan Plateau mostly decreased, especially at the southern edge of the plateau. Below the 500-m contour line at the southern edge (region B), more precipitation is produced. Moreover, the precipitation amounts in regions $\mathrm{A}$ and $\mathrm{C}$ also increase, corresponding to the positive differences in the total precipitation and vertically integrated moisture content in the same regions (Figs. 5b, 7b). Figure 8b further confirms that the difference of the total precipitation amount in the shortterm NWP experiments result from the large-scale precipitation, which exhibits similar patterns to Fig. 7a.

With the development of model integration, the day-3 differences (Fig. 8c, d) more resemble the long-term climatological mean results. The area with negative values at the main body of the Tibetan Plateau increases, and the two maximum centers with positive differences on the lee side of the Tibetan Plateau around the Sichuan basin converge to one center, as in the long-term results (Figs. 5b, 7b). The results from Fig. 8 prove that the precipitation differences develop shortly after the model initialization and approach the differences in the climatological mean state.

In addition to the precipitation amount, the precipitation frequency and intensity are two primary metrics that describe the precipitation characteristics. To further check the differences in the simulated precipitation between MqCAM5 and M-CAM5, Fig. 9 shows the changes of average hourly precipitation frequency and mean hourly intensity obtained from the day-3 results for the total and largescale precipitation, respectively. The hourly frequency is determined with a precipitation threshold higher than $0.5 \mathrm{~mm} \mathrm{day}^{-1}$ by using hourly data. The mean hourly intensity is the composite precipitation amount when the model rains. For detailed procedures in calculating these two metrics, please refer to Zhang and Chen (2016).

Comparing the results in Fig. 9 with those in Fig. 8c, d, it is seen that the changes in both frequency and intensity contribute to the differences in the precipitation amount. At the main body of the Tibetan Plateau, both the frequency and intensity values decrease in the total and large-scale precipitation. At the low-altitude regions of the southern edge of the Tibetan Plateau and over the Sichuan basin, the frequency and intensity values increase, corresponding to the increase in precipitation amount (Fig. $8 \mathrm{c}, \mathrm{d}$ ). The consistent changes in the frequency and intensity suggest that the moisture divergence term fundamentally alters the precipitation climatology around the Tibetan Plateau. The model precipitates less frequently with reduced intensity at the high parts of steep slopes, whereas the model yields more frequent precipitation with increased intensity at the low parts.

To further quantify the relative magnitude of the moisture divergence term against the original moisture advection term, an additional group of sensitivity experiments were conducted. In these experiments, M-CAM5 and MqCAM5 were respectively initialized at June 30 of a year (1988) and continuously integrated until August 2 of 1988. The models dumped diagnostic variables at each time step (every $30 \mathrm{~s}$ ). The entire month of July is selected for further analysis. For each model, the moisture tendency from the adiabatic term $\left(-\vec{V}_{3} \nabla_{3} q\right.$ for M-CAM5 and $-\nabla_{3} \cdot\left(\vec{V}_{3} q\right)$
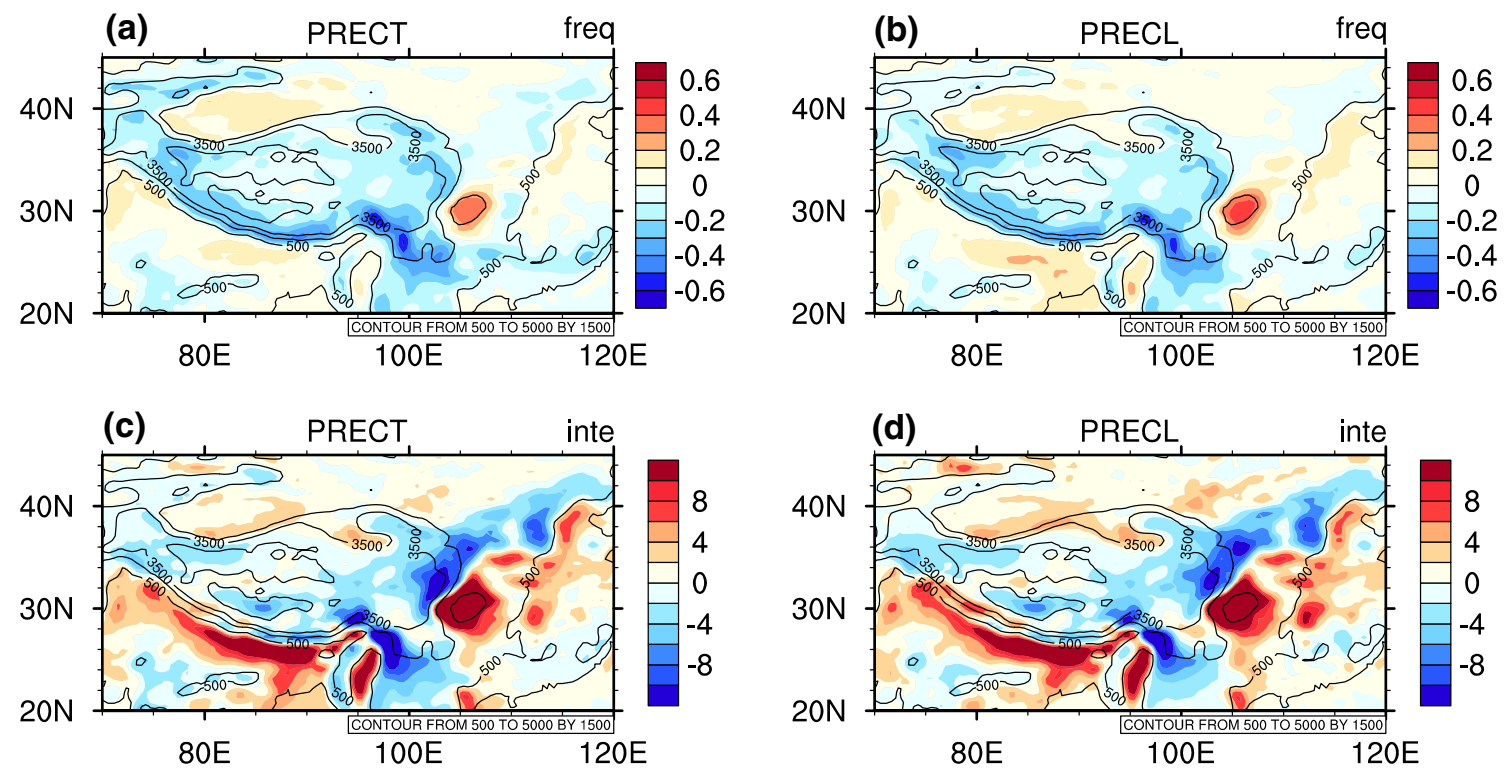

Fig. 9 Changes in precipitation frequency (freq, unit: fraction) and intensity (inte, unit: $\mathrm{mm} \mathrm{day}^{-1}$ ) between Mq-CAM5 and M-CAM5 for the total precipitation (PRECT) and large-scale precipitation (PRECL) obtained from the day- 3 ensemble 
for Mq-CAM5) at each time step is calculated by taking the difference between the total moisture tendency and the moisture tendency only from model physics (the unit is scaled to $\mathrm{K} \mathrm{day}^{-1}$ ). Thus, the difference in the adiabatic tendency between Mq-CAM5 and M-CAM5 (Mq-CAM5 minus M-CAM5) can be viewed as an implicit quantification of the moisture divergence tendency.

As shown in Fig. 10a, the monthly mean result of the original moisture advection tendency (vertically integrated) in M-CAM5 suggests that the adiabatic process creates a positive change in the moisture tendency. The most evident positive maxima are located at the southern edge of the
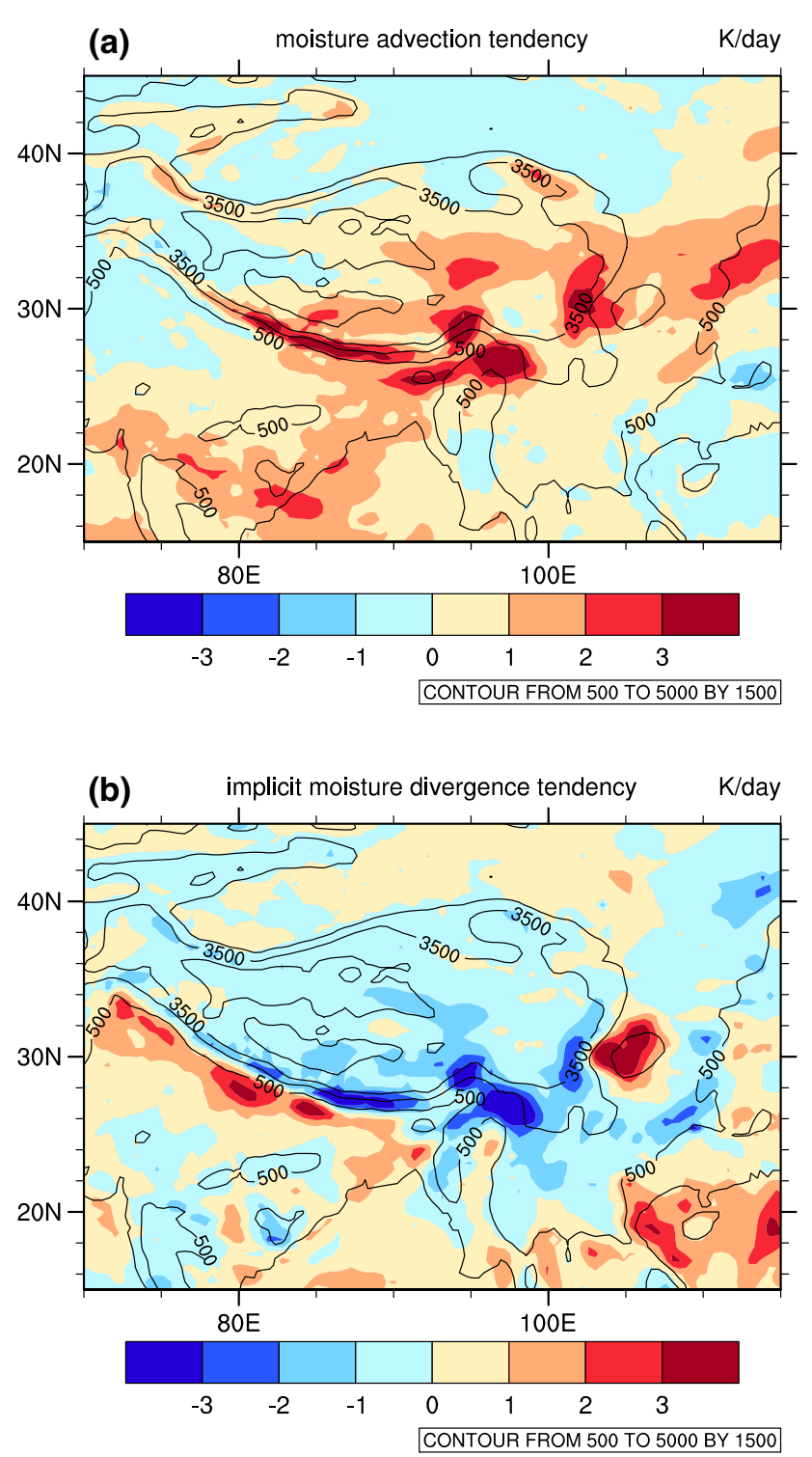

Fig. 10 Single monthly mean (July 1988) of a moisture advection tendency (vertically integrated) derived from M-CAM5, and b implicit moisture divergence tendency derived from Mq-CAM5 and M-CAM5, unit: K day ${ }^{-1}$
Tibetan Plateau, between the 500 and $3500 \mathrm{~m}$ orographic height contour lines. The tendency from the implicit moisture divergence term (Fig. 10b) shows negative values over the main body of the plateau. The most evident minima at the southern edge just offset the maxima values in Fig. 10a. The absolute values of the positive (Fig. 10a) and negative (Fig. 10b) tendencies are generally similar. Below the 500-m contour line at the southern edge, the moisture divergence term contributes to a larger positive tendency than the original advection tendency over this region. This result highlights the significant magnitude and important role of the moisture divergence term in modulating the moisture content around the Tibetan Plateau.

\section{Summary and discussion}

In this paper, a series of contrasting tests were conducted to investigate the impact of moisture divergence on the simulated orographic precipitation. By adding an additional moisture divergence term in the advection equation of an AGCM, the results demonstrated the large sensitivity of orographic precipitation to this additional term, which fundamentally influences the moisture saturation and condensation by redistributing the water vapor. The added term enables the model to precipitate less at the high parts of steep slopes, and more at the low-altitude regions, offsetting the original systematic model errors. The changes in the precipitation amount are contributed by consistent variations in both frequency and intensity, and emerge shortly after the model initialization.

The large sensitivity of the precipitation field is only evident at steep mountainous regions (figure not shown), and is hardly seen at regions whose surfaces are covered by plains or oceans. As stated in the introduction, high mountains exert great friction to the surrounding airflows, and the additional moisture divergence term enables the model to dissipate/absorb more moisture at the steep slopes that are controlled by strong divergent/convergent flows. Therefore, the redistributed water vapor content can fundamentally alter the simulation of the annual mean precipitation, showing large sensitivity and offsetting the original errors.

The results of this study have important implications. It reminds us two facts relevant to the simulations and forecasts of precipitation around large mountains like the Tibetan Plateau. First, precipitation around steep slopes is well sensitive to the distribution of column precipitable water. Second, the moisture divergence and convergence around a steep terrain can greatly impact the distribution of column precipitable water, and further modulate the precipitation amount. It should be pointed out that whether the moisture content around the steep terrain is overestimated by CAM5 remains elusive due to our current inability to find clear observational 
constraints that favor some results over others (Figs. 2, 3). Nevertheless, this does not hinder the fact that the moisture tendency produced by the additional divergence term is able to effectively mitigate the systematic errors in orographic precipitation. From a pragmatic point of view, this additional divergence term can properly adjust the simulated climate to a more realistic state. In the weather forecast mode, the models with and without this additional term quickly produce large differences in orographic precipitation. Thus, this approach will help researchers who are interested in improving the forecasting capability of global models. In this sense, this approach shares a similar philosophy with the error suppression strategies used in operational forecast practices (e.g., Wallace 1975; Buizza et al. 1999; Magnusson et al. 2013b).

The impact of this moisture divergence term could also be achieved in the form of a parameterization scheme, specially designed for mountainous regions. This approach could be preferable than solving an artificial advection equation globally, as done in this study. Moreover, the approach and findings in this study might also help those who are interested in the impact of more realistic orographic precipitation on the local climate (e.g., the land surface process). This could be another benefit of this study.

Acknowledgments The authors are grateful to two anonymous reviewers for the comments, which helped improve the original manuscript. This research was supported by the National Natural Science Foundation of China (Grants 41505066, 41322034 and 41221064), and the Basic Scientific Research and Operation Foundation of the Chinese Academy of Meteorological Sciences (Grants $2015 Z 002$ and 2015Y005).

Open Access This article is distributed under the terms of the Creative Commons Attribution 4.0 International License (http://creativecommons.org/licenses/by/4.0/), which permits unrestricted use, distribution, and reproduction in any medium, provided you give appropriate credit to the original author(s) and the source, provide a link to the Creative Commons license, and indicate if changes were made.

\section{References}

Alves L, Marengo J (2010) Assessment of regional seasonal predictability using the PRECIS regional climate modeling system over South America. Theor Appl Climatol 100:337-350

Bretherton CS, Park S (2009) A new moist turbulence parameterization in the Community Atmosphere Model. J Clim 22:3422-3448

Buizza R, Milleer M, Palmer TN (1999) Stochastic representation of model uncertainties in the ECMWF ensemble prediction system. Q J R Meteorol Soc 125:2887-2908

Codron F, Sadourny R (2002) Saturation limiters for water vapour advection schemes: impact on orographic precipitation. Tellus $\mathrm{A}$ 54(4):2002

Danard M, Zhang Q, Kozlowski J (1993) On computing the horizontal pressure gradient force in sigma coordinates. Mon Weather Rev 121:3173-3183
Gettelman A, Morrison H, Ghan SJ (2008) A new two-moment bulk stratiform cloud microphysics scheme in the Community Atmosphere Model, version 3 (CAM3). Part II: single-column and global results. J Clim 21:3660-3679

Gulizia C, Camilloni I (2015) Comparative analysis of the ability of a set of CMIP3 and CMIP5 global climate models to represent precipitation in South America. Int J Climatol 35:583-595

Huang B, Hu Z-Z, Jha B (2007) Evolution of model systematic errors in the tropical Atlantic basin from coupled climate hindcasts. Clim Dyn 28:661-682

Huffman GJ et al (2007) The TRMM multisatellite precipitation analysis (TMPA): quasi-global, multiyear, combined-sensor precipitation estimates at fine scales. J Hydrometeorol 8:38-55

Iacono MJ, Delamere JS, Mlawer EJ, Shephard MW, Clough SA, Collins WD (2008) Radiative forcing by long-lived greenhouse gases: calculations with the AER radiative transfer models. J Geophys Res Atmos 113:D13103

Kasahara A (1974) Various vertical coordinate systems used for numerical weather prediction. Mon Weather Rev 102:509-522

Lin S-J (2004) A “vertically Lagrangian” finite-volume dynamical core for global models. Mon Weather Rev 132:2293-2307

Liu X et al (2012) Toward a minimal representation of aerosols in climate models: description and evaluation in the Community Atmosphere Model CAM5. Geosci Model Dev 5:709-739

Machenhauer B (1979) The spectral method, in numerical methods used in atmospheric models. World Meteorological Organization, Geneva

Magnusson L, Alonso-Balmaseda M, Molteni F (2013a) On the dependence of ENSO simulation on the coupled model mean state. Clim Dyn 41:1509-1525

Magnusson L, Alonso-Balmaseda M, Corti S, Molteni F, Stockdale T (2013b) Evaluation of forecast strategies for seasonal and decadal forecasts in presence of systematic model errors. Clim Dyn 41:2393-2409

Mauritsen T et al (2012) Tuning the climate of a global model. J Adv Model Earth Syst 4:M00A01

Mehran A, AghaKouchak A, Phillips TJ (2014) Evaluation of CMIP5 continental precipitation simulations relative to satellite-based gauge-adjusted observations. J Geophys Res Atmos. doi:10.100 2/2013JD021152

Mlawer EJ, Taubman SJ, Brown PD, Iacono MJ, Clough SA (1997) Radiative transfer for inhomogeneous atmospheres: RRTM, a validated correlated-k model for the longwave. J Geophys Res 102:16663-16682

Morrison H, Gettelman A (2008) A new two-moment bulk stratiform cloud microphysics scheme in the Community Atmosphere Model, version 3 (CAM3). Part I: description and numerical tests. J Clim 21:3642-3659

Neale RB, Richter JH, Jochum M (2008) The impact of convection on ENSO: from a delayed oscillator to a series of events. J Clim 21:5904-5924

Park S, Bretherton CS (2009) The University of Washington shallow convection and moist turbulence schemes and their impact on climate simulations with the Community Atmosphere Model. J Clim 22:3449-3469

Park S, Bretherton CS, Rasch PJ (2014) Integrating cloud processes in the Community Atmosphere Model, version 5. J Clim 27:6821-6856

Phillips TJ et al (2004) Evaluating parameterizations in general circulation models: climate simulation meets weather prediction. Bull Am Meteorol Soc 85:1903-1915

Richter JH, Rasch PJ (2008) Effects of convective momentum transport on the atmospheric circulation in the Community Atmosphere Model, version 3. J Clim 21:1487-1499

Rodwell MJ, Palmer TN (2007) Using numerical weather prediction to assess climate models. Q J R Meteorol Soc 133:129-146 
Simmons AJ, Burridge DM (1981) An energy and angular-momentum conserving vertical finite-difference scheme and hybrid vertical coordinates. Mon Weather Rev 109:758-766

Su F, Duan X, Chen D, Hao Z, Cuo L (2013) Evaluation of the global climate models in the CMIP5 over the Tibetan Plateau. J Clim 26:3187-3208

Wallace JM (1975) Diurnal variations in precipitation and thunderstorm frequency over the conterminous United States. Mon Weather Rev 103:406-419

Williamson DL, Rasch PJ (1989) two-dimensional semi-Lagrangian transport with shape-preserving interpolation. Mon Weather Rev 117:102-129

Williamson DL, Rasch PJ (1994) Water vapor transport in the NCAR CCM2. Tellus A 46:34-51

Xie S, Ma H-Y, Boyle JS, Klein SA, Zhang Y (2012) On the correspondence between short- and long-time-scale systematic errors in CAM4/CAM5 for the year of tropical convection. J Clim 25:7937-7955

Xu Y, Gao X, Giorgi F (2010) Upgrades to the reliability ensemble averaging method for producing probabilistic climate-change projections. Clim Res 41:61-81

Yanai M, Esbensen S, Chu J-H (1973) Determination of bulk properties of tropical cloud clusters from large-scale heat and moisture budgets. J Atmos Sci 30:611-627
Yu R (1994) A two-step shape-preserving advection scheme. Adv Atmos Sci 11(4):479-490

Yu R, Li J, Zhang Y, Chen H (2015) Improvement of rainfall simulation on the steep edge of the Tibetan Plateau by using a finitedifference transport scheme in CAM5. Clim Dyn 45:2937-2948

Zhang Y, Chen H (2016) Comparing CAM5 and super-parameterized CAM5 simulations of summer precipitation characteristics over continental East Asia: mean state, frequency-intensity relationship, diurnal cycle and influencing factors. J Clim 29:1067-1089

Zhang Y, Li J (2013) Shortwave cloud radiative forcing on major stratus cloud regions in AMIP-type simulations of CMIP3 and CMIP5 models. Adv Atmos Sci 30(3):884-907

Zhang G, McFarlane N (1995) Sensitivity of climate simulations to the parameterization of cumulus convection in the Canadian Climate Centre general circulation model. Atmos Ocean 33:407-446

Zhang Y, Yu R, Li J, Chen H (2013) An implementation of a leapingpoint two-step shape-preserving advection Scheme in the highresolution spherical latitude-longitude grid (in Chinese with English Abstract). Acta Meteorol Sin 71(6):1089-1102

Zhang Y, Chen H, Yu R (2015) Simulations of stratus clouds over Eastern China in CAM5: sources of errors. J Clim 28:36-55 